\title{
France, Switzerland 'must pay more' for LHC
}

Munich. Germany has thrown a spanner into negotiations over the construction of Europe's planned Large Hadron Collider (LHC) by unexpectedly demanding that France and Switzerland jointly provide an additional 10 per cent of the collider's costs, in addition to their regular contributions to the European Laboratory for Particle Physics (CERN).

Germany's demand dominated last Friday's meeting of the CERN council, which many had hoped would give formal approval to the construction of the LHC. In particular, negotiations on the contentious issue of inflation-linked rises in contributions seemed to be reaching compromise.

But the German delegation, acting under instructions Bonn (and with the formal backing of the United Kingdom), demanded that CERN's two host countries, France and Switzerland, contribute an extra 10 per cent of the estimated SFR2.6 billion (US\$1.96 billion) costs of the LHC programme.

Neither country is likely to be in a position to raise a significant portion of such a figure, particularly in view of the pressures on France's science budget (see Nature 369, $511 ; 1994)$, and Switzerland's need to find extra funds in order to participate in the European Commission's Framework Programme (see Nature 369, 264; 1994).

CERN president Hubert Curien adjourned the meeting in order to give delegates more time to discuss the matter with their governments. Before doing so, however, he elicited a vote to proceed with the LHC from 17 of its member countries.

Curien hopes to reconvene the meeting before the summer holidays to allow Germany and the United Kingdom to vote. But he also accepts that negotiations may take until the next planned council meeting in September.

Meanwhile, he believes that the positive vote from the majority of countries will give CERN more weight in its negotiations with non-member states, such as the United States, Japan and Canada, which it hopes will contribute to the LHC programme. This currently has a shortfall of SFr 500 million in its budgeted funds.

The issue of whether France and Switzerland should pay a significant premium for the privilege of being host countries to CERN (the laboratory straddles the border between the two countries) has been raised on previous occasions. The idea has wide support among member states, who realize the value of the laboratory to its two local economies. As countries such as Spain have pointed out, France enjoys a financial return, measured by the total of value of contracts won by French enterprises, more than double its contribution; Switzerland's return is six times as much.

Switzerland has in general been sensitive to this issue, and has made several $a d$

hoc payments over the years to contribute to specific programmes. It announced in December that it was prepared to make a significant contribution above its normal subscription to the building of the LHC.

But, to the annoyance of Germany which feels it has shouldered a large portion of CERN's costs in the past - France has held back. Only in the past few weeks has it made a comparable statement.

Neither the Swiss nor the French offers have figures attached, though current estimates suggest neither is much above

\section{IMAGE UNAVAILABLE FOR COPYRIGHT REASONS}

SFr25 million. Both countries appear to be waiting as long as possible to see how far non-member states are prepared to meet the expected budgetary shortfall.

The sudden demand from Germany that the two countries should pay between them a SFr260 million premium over ten years received mixed responses from other member states, frustrated that Germany appeared to be spoiling an opportunity to reach consensus on LHC.

There were also murmurings about Germany's actions being dictated by a higher political agenda, such as rumoured attempts to link the CERN issue to other political decisions. But most accepted that it is primarily Germany's tight budget situation, a result of reunification, which prevents it from being as generous as previously.

There was also some feeling of support for the way that Germany criticized France for not paying a premium on its contributions to CERN in recognition of the country's host status.

\section{Britain argues for}

London. Ken Pounds, professor of astronomy at the University of Leicester and chief executive of Britain's newly-formed Particle Physics and Astronomy Research Council, said on Monday that it was essential for Britain to put strong financial constraints on the costs of the planned Large Hadron Collider (LHC).

Speaking at the opening of an international conference on particle accelerator technology, Pounds said that in recent years funding available to British scientists to work on the results of experiments at CERN had fallen by a factor of three. "This is like paying high fees to join a golf club, and then having no money left to buy any balls."

Pounds, who expressed optimism that
Hermann Strub, the German delegate, refused to comment on Germany's tactics after the meeting. But he claims that a 10 per cent premium for host countries of international laboratories has become the norm, citing the Joint European Torus (JET) in Britain, and the European Synchrotron Radiation Facility (ESRF) in France.

Meanwhile a second issue, which had threatened to delay approval of the LHC, seems closer to resolution. Germany and the United Kingdom have both been keen to hold down annual inflation-linked rises in contributions by changing voting rules so that such rises could be vetoed by any of CERN's 19 member states. (see Nature 369, $509 ; 1994)$. At present, a rise can be agreed by a simple majority of member states, provided their contributions represent at least 55 per cent of the budget.

CERN management refused to accept that this should now require unanimous approval. It pointed out that it would allow any country, no matter how small its financial contribution, to block a rise in budget, seriously reducing CERN's buying power.

Negotiations in the last few weeks between CERN director-general Christopher Llewellyn Smith and Germany and the UK had succeeded in moving towards a compromise whereby contributions would be fixed at 1994 levels until 1997, and then reviewed at the time of the major LHC programme review.

In addition, a compromise voting procedure, suggested by Belgium, which would require a majority representing around twothirds of the budget, is under consideration. The figure finally arrived at is critical, as Germany and the United Kingdom together contribute around 36 per cent of CERN's budget, and could combine to block a rise. That makes some countries, such as Switzerland, uneasy, but a compromise between these positions seems within reach. Alison Abbott

\section{'firm cost control'}

the French would agree to make a "substantial" additional contribution along the lines being demanded by Germany (see above), said that Britain is keen for the LHC to proceed. "But we felt this was the moment to say: hang on."

David Davies, parliamentary secretary in the Office of Public Service and Science, said that the UK was convinced that the LHC was "the right way forward" for high-energy physics. But, reflecting Britain's desire to see CERN enlarged into a "fully global organization", he said that large-scale facilities such as the LHC "cannot - and indeed should not - be afforded on a national or even a regional basis".

M. V. 